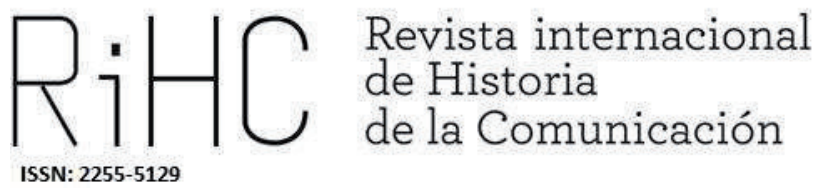

\title{
CRÓNICAS JORNALÍSTICAS NO FEMININO: IMPRESSÕES DE UM QUOTIDIANO INSTÁVEL NO FINAL DO ESTADO NOVO
}

Journalistic chronicles in the feminine: impressions of an unstable daily life at the end of the Estado Novo

DOI: http://dx.doi.org/10.12795/RiCH.2021.i16.05

Recibido: 1-5-2021

Aceptado: 8-6-2021

Publicado:30-6-2021

José Cândido de Oliveira Martins*

Universidade Católica Portuguesa (UCP - FFCS), Portugal

cmartins@ucp.pt

ORCID (i) https://orcid.org/0000-0002-7970-8794

\footnotetext{
${ }^{1}$ Estudo desenvolvido no âmbito do Projeto Estratégico do Centro de Estudos Filosóficos e Humanísticos (CEFH) UIDB/00683/2020, financiado pela Fundação para a Ciência e Tecnologia (FCT). 
Resumen: Nos anos finais da ditadura do Estado Novo, mesmo com a actuação da censura prévia e de outras constrições, a imprensa periódica desempenhou um papel relevante de sensibilização crítica, nomeadamente ao nível da consciencialização do lugar e identidade do feminino. Através de um "corpus" de três livros de crónicas escritas nessa época por três escritoras (Maria Judite de Carvalho, Agustina Bessa-Luís e Maria Teresa Horta), procura-se desenvolver uma reflexão em torno da problematização da questão da Mulher, através da flexibilidade e abertura do género da crónica, simultaneamente jornalística e literária. Adoptando estilos diversos, as três escritoras apresentam um apreciável contributo para essa reflexão em torno da condição feminina, questão muito discutida na época.

Palabras clave: crónica, escritoras portuguesas, feminino, jornalismo, mulher.

\begin{abstract}
In the final years of the Estado Novo dictatorship, even with the prior censorship and other constraints, the periodical press played a relevant role in raising critical awareness, particularly in terms of raising awareness of the place and identity of women. Through a "corpus" of three books of chronicles written at that time by three writers (Maria Judite de Carvalho, Agustina Bessa-Luís and Maria Teresa Horta), we seek to develop a reflection around the problematization of the issue of women, through the flexibility and openness of the genre of the chronicle, simultaneously journalistic and literary. Adopting different styles, the three writers make an appreciable contribution to this reflection on the feminine condition, a much-discussed issue at the time.
\end{abstract}

Keywords: chronicle, Portuguese writers, feminine, journalism, woman.

\title{
Retrato de um Portugal cinzento
}

A partir do golpe militar de Maio de 1926 e da posterior Constituição de 1933, o regime político português do Estado Novo (1933-1974), protagonizado pelo Dr. António Oliveira Salazar, moldou a política, a sociedade e a cultura portuguesas durante quase meio século, através de um prolongado regime ditatorial, constitucionalmente corporativo, sem liberdades fundamentais e com um sistema de ensino superiormente controlado, num caso singular de longa duração de um regime (cf. Rosas, 2015: 183 ss.).

Entre outras marcas fundamentais deste governo, com etapas sucessivas ao longo de décadas, convém salientar algumas, pelo seu enorme impacto social: i) a instituição de um regime de partido único (União Nacional), com a supressão de liberdades essenciais; ii) a manutenção eficaz do sistema de Censura, que incluía o activo controlo da publicação de livros e de periódicos, com aparente liberalização a partir de 1968, com o "Exame prévio" de Marcelo Caetano (cf. Franco, 1993; Tengarrinha, 2006); iii) a manutenção do Império colonial, contra todas as críticas internas e internacionais; iv) a actuação de uma poderosa máquina de propaganda, na senda do Secretariado de Propaganda Nacional (SPN), criado em 1933, com António Ferro, sucessivamente rebatizado (cf. Paulo \& Torgal, 2015: 181 et passim); v) e a existência algumas 
organizações de controlo ideológico, como a Mocidade Portuguesa, aliás à imagem do que também acontecia em outras ditaduras coevas, em Espanha ou em Itália.

Nes contexto, não se deve esquecer a secção da Mocidade Portuguesa Feminina (MPF), sob o patrocínio do Ministério da Educação, e a Obra das Mães pela Educação Nacional (OMEN) - criadas em 1936-37, sendo estas mocidades reestruturadas em 1966 -, com o objectivo expresso de estimular a acção educativa da família, em cooperação desta com a escola, fomentando assim a um amplo programa de formação nacionalista da juventude portuguesa. Nos mais diversos aspectos da vida quotidiana e em vários estractos sociais - do enquadramento legal ao papel no sistema educativo ou às práticas de educação física -, o lugar e a missão da Mulher estavam devidamente enquadrados pela política do Estado Novo, sendo muito reveladora a história das organizações e movimentos femininos nesta época (cf. Pimentel, 2000). A função social das mulheres e das mães estava fortemente condicionada por valores caros à organização e à ideologia do regime: papel da mulher mãe e dona de casa ("fada do lar"), na sua função maternal e procriadora, educativa e assistencial. Condicionada por preconceitos diversos e pelas regras da conservadora moral católica, prevê-se a imagem da mulher no espaço da família, dependente do pai ou do marido, tendencialmente apartada de muitas funções profissionais autónomas, quer no mercado de trabalho, quer sobretudo no espaço público e na vida política.

É este Portugal cinzento e fechado, com uma elevada taxa de analfabetismo e uma imprensa controlada pelo activo sistema da Censura que vamos encontrar nos anos de 1960 e início de 1970, mau grado a tímida abertura de liberalização ensaiada por Marcelo Caetano (cf. Ramos, 2015: 696 ss.). É certo que existiam algumas formas de oposição, mais ou menos clandestinas, sobretudo de natureza política. Estamos perante um tempo que se segue aos "anos de chumbo" da "lenta agonia do salazarismo" (cf. Rosas, 1994: 503), abalado sucessivamente por relevantes factos com enorme impacto na sociedade portuguesa e mesmo no estrangeiro, com destaque para alguns: i) a fraudulenta eleição para a presidência da República, em 1958, com a eleição do candidato do regime (general Américo Thomaz) e o posterior assassinato do candidato independente e opositor ao regime, Humberto Delgado, em 1965; ii) a eclosão da chamada Guerra Colonial nos territórios das "colónias" do Império português, a partir de 1961, que se prolongará até 1974 (cf. Ramos, 2015: 679 ss.); iii) a substituição de Oliveira Salazar por Marcelo Caetano em 1968, devido a um grave acidente do velho Presidente do Conselho, que morrerá em 1970; iv) as greves estudantis nas importantes universidades de Coimbra e de Lisboa; v) as difíceis relações com o Vaticano, incluindo a tensa visita de Paulo VI a Fátima, devido à questão colonial; vi) e, apenas a título de exemplo da longa vigência Censura na etapa final do regime, o caso do saque e extinção da Sociedade Portuguesa de Escritores, após a atribuição de um importante prémio literário ao escritor Luandino Vieira, em 1965. 
Escusado será anotar que estes e outros factos similares não aparecem referidos nas crónicas destas autoras - Maria Judite de Carvalho, Agustina Bessa-Luís e Maria Teresa Horta -, fruto da acção vigilante da Censura. Aliás, em 1972, também na senda da revolução encetada pelo internacional Maio de 68, é publicada em Portugal uma obra que perturba profundamente a aparente pacatez do regime - referimo-nos às Novas Cartas Portuguesas, da autoria de três escritoras (Barreno, Horta e Costa, 2010: xviii), logo tomada como publicação de "conteúdo insanavelmente pornográfico e atentatório da moral pública". Segue-se imediatamente a apreensão do livro e o processo judicial movido contra as "três Marias", incluindo interrogatórios na polícia política (PIDE/DGS), num caso com notável impacto jornalístico interno, mas também a nível internacional.

Em momentos diferentes da sua evolução, logo a partir do golpe militar de 1926, a ditadura militar e sobretudo o Estado Novo, em 1933, foi aprovando diversos diplomas legislativos de modo a legitimar os procedimentos de aplicação da Censura prévia, por um longo período de cerca de meio século, até à Lei de Imprensa de 1972, em pleno governo marcelista (cf. Rodrigues, 1980: 69 ss.). Perante a omnipresente acção da Censura, mesmo em tempos da proclamada abertura marcelista, a escritora Maria Velho da Costa (cf. 1973: 55) - umas das autoras do livro apreendido das Novas Cartas Portuguesas, além de levada a julgamento - satiriza a acção nefasta do acto censório da criação intelectual e da própria imprensa, propondo uma Ova Ortegrafia nestes termos: "Ecidi escrever ortado; poupi assim o rabalho a que me orta."

É oportuno também relembrar que neste contexto político-social, a cultura e a literatura também sofriam as consequências do fechamento, da falta de liberdade e da actuação da Censura. $O$ caso particular das mulheres escritoras, que sempre existiram em muito menor número face aos escritores homens no campo literário, quer nas circunstâncias gerais da sociedade do final do Estado Novo, quer na exiguidade do sistema literário português, muito confinado à capital, Lisboa, e pouco mais, revela-se peculiar. Uma coisa parece indiscutível neste cenário: através da omnipresente Censura, a imprensa é arma política, mais ou menos controlada, ao serviço da ideologia dominante: "A imprensa, visando a «reabilitação moral» da Nação, deve, de igual forma, deixar de lado as notícias que atentem contra a "dissolução de costumes», como notícias sobre «suicídios», «infanticídios», ou ainda, anúncios de "astrólogos, bruxas, videntes» ou de «empregos de moral suspeita»" (Paulo e Torgal, 2015: 181). Era com estas constrições que também nos anos finais do Estado Novo se podia escrever na imprensa.

Neste contexto, revela-se muito desafiadora a leitura da colaboração de mulheres escritores na imprensa desta época. Para isso, escolhemos um corpus representativo, constituído por três autoras reconhecidas pela crítica de então, mas ainda mais pela recepção actual: Maria Judite de Carvalho (1921-1998), autora de A Janela Fingida, recolhendo crónicas jornalísticas de 1968-1969; Agustina Bessa-Luís (1922-2019), escritora de Alegria do Mundo, recolhendo crónicas da imprensa dos anos de 1965-69; 
e Maria Teresa Horta (1937), a única ainda viva, publicando Quotidiano Instável, enquanto recolha de crónicas da imprensa dos anos de 1968-1972. Outras cronistas poderiam ser convocadas para um trabalho desta natureza - Fernanda de Castro, Irene Lisboa, Isabel da Nóbrega, Luísa Dacosta, Maria Ondina Braga, Natália Correia, Natércia Freire, entre outras (cf. Carmo, 2018) -, mas convém cingirmo-nos a um corpus mais selecto e adequado a um breve estudo, sem deixar de ser representativo.

Nos três casos referidos, estamos perante escritoras que escrevem com regularidade para a imprensa da época, em colunas periódicas, mantendo assim uma presença relevante no espaço público. Simultaneamente, esta escrita cronística mantém uma estreita ligação com a obra literária de cada uma das autoras, ora explorando temáticas afins, ora complementando aspectos e reflexões que não cabem totalmente em géneros específicos cultivados (como o romance, o conto ou a poesia), mas sim na flexibilidade do género cronístico. Por outras palavras, as crónicas destas escritoras são igualmente bem demonstrativas de certas dominantes da sua criação literária, por um lado; e, por outro, da valorização das colunas jornalísticas enquanto singular espaço de intervenção.

Ao mesmo tempo, estamos diante de um conjunto expressivo de crónicas femininas (embora estas autoras tenham escrito outros livros de crónicas), que coincidem temporalmente com os referidos últimos anos do regime do Estado Novo, já na sua fase final. O nosso propósito, enquanto questões de investigação, é tríplice: i) analisar temática e criticamente nestes três livros de crónicas o modo como as três escritoras abordam o tema da Mulher e a definição do feminino enquanto condição na sociedade da época; ii) ao mesmo tempo, mais indirectamente, verificar como se posicionam face a esse contexto, a partir do seu lugar de escritoras-cronistas; iii) lateralmente, também nos deteremos numa caracterização do singular tratamento do género da crónica, consoante o estilo original que cada escritora imprime a esta forma discursiva tão flexível e moldável, aliás de acordo com a poética literária de cada uma destas autoras.

Por conseguinte, na impossibilidade de nos determos em muitos dos temas abordados pelas três autoras, o tópico central será então o de indagar, em três livros de crónicas, a atenção concedida à Mulher e ao feminino, o mesmo é dizer, ao direito de falar do corpo, do desejo e da sexualidade, num tempo em que imperava o recato e o silêncio, a ditadura da moral e dos bons costumes, pelo que qualquer pronunciamento adquire um manifesto significado político. Neste contexto especial de uma sociedade assumidamente patriarcal, com papéis sociais e sexuais pré-definidos para a Mulher, qualquer afirmação no domínio temático enunciado não só implicava imensa coragem, mas também significava um desafio e uma considerável ruptura, como, aliás, enunciado pelas autoras das Novas Cartas Portuguesas: "Se a mulher se revolta contra o homem nada fica intacto" (Barreno; Horta; Costa, 2010: 143).

Entre outros factores que devemos ter em conta nesta leitura assim focada, merecem realce três: primeiro, na altura em que escreviam estas crónicas, estas escritoras já 
tinham sido objecto de reconhecimento no campo literário; segundo, eram autoras que cultivavam outros géneros literários mais consagrados, como o romance ou a poesia; terceiro, como sugerido, no seu acto de escrita, enfrentavam as limitações coercivas de um sistema de Censura que não permitia uma efectiva liberdade de expressão, condicionando fortemente o que podiam escrever, seja sobre a forma de livro, seja sob o género de crónicas jornalísticas. Por exemplo, nas crónicas de Maria Teresa Horta (2019: 79, 94) menciona-se, repetidamente, um "tempo peganhento" ou a "cor de chumbo" do céu desse Portugal no lento final do Estado Novo. Referências como estas ganham uma expressividade simbólica bem proporcional à contenção metafórica da linguagem.

Além de uma forma de auferir algum rendimento (este tipo de colaboração nos jornais era habitualmente paga), as crónicas nos jornais eram sobretudo um púlpito ou um modo de pronunciamento público, numa coluna jornalística fixa e regular, espaço mairoritariamente ocupado por homens. Por conseguinte, com as limitações referidas, esta forma de intervenção sócio-cultural revestia-se de uma apreciável relevância simbólica, que não deve ser descurada ou minimizada.

\section{A cidade através da janela de Maria Judite de Carvalho}

Quando publica o volume de crónicas A Janela Fingida (1ạ ed., 1975), logo a seguir à Revolução do 25 de Abril de 1974, uma das suas várias obras de crónicas, Maria Judite de Carvalho é então uma escritora com obra publicada e distinguida, cultivando sobretudo o conto e o romance. Depois de ter sido agraciada com o Prémio Camilo Castelo Branco, a autora de Tanta Gente, Mariana (de 1959) publica na Seara Nova este volume de crónicas.

Nas breves crónicas escritas sobretudo para o jornal Diário de Lisboa (1968-1969) conhecido jornal de oposição ao regime do Estado Novo, tendo como director Joaquim Manso -, a autora opta resolutamente por um tipo de texto dominado por alguns traços maiores - desde a aguda observação do quotidiano, sem afastar a memória das coisas (sobretudo através de uma poética vibrátil dos sentidos), até à pulsão ficcional e a uma difusa melancolia. O curioso é analisar como a inventividade deste tipo de crónicas, da coluna regular "Rectângulos da Vida", encaixa na dimensão informativa do ethos jornalístico contemporâneo (cf. Moura, 2018: 20 et passim). No mesmo jornal, também assinou textos sob o pseudónimo de Emília Bravo, no suplemento "Mulher", dando depois origem ao volume dos Diários de Emília Bravo. 
A par da sensível observação pessoal, várias dessas crónicas têm uma génese ancorada em notícias do momento, tal como veiculadas pela imprensa: "Vem isto a propósito da "Estranha aventura de um casal argentino», noticiada a 4 deste mês (...)" (Carvalho, 2019: 49); na abertura de outra crónica: "Há dias, ao ler o jornal, lembrei-me de (...)" (Carvalho, 2019: 111); e ainda em outro incipt: "Leio no jornal que os americanos vão deixar na Lua (...)" (Carvalho, 2019: 131). Afinal, reiteradamente, a imprensa diária também se constitui como fonte de inspiração e de reflexão.

De facto, a crónica escrita por uma sensibilidade literária tem a singularidade da metamorfose relatada no primeiro texto, quando se refere ao "médico [que] substituíra os olhos do banqueiro pelos olhos de um poeta lírico que morrera atropelado" (Carvalho, 2019: 19). Também a cronista vê o mundo através de um olhar de ternura quase lírica, embora melancólica. Por mais que a crónica mergulhe no quotidiano, não esconde nunca a sua perspectiva de fundo, podendo afirmar-se a hibridez entre o jornalístico e o literário: "Mas tudo isto é literatura" (Carvalho, 2019: 20). E sobretudo, sente-se uma mundividência quase animista, que confere vida e sensibilidade a tudo, mesmo aos mais inesperados objectos: "De resto não acredito na matéria totalmente bruta, acho que as coisas pensam, embora pensem errado, ou, pelo menos, de um modo estranho" (Carvalho, 2019: 23). Daqui decorre um traço maior do género da crónica, enquanto forma de escrita de difícil definição, salientando-se a sua congenial hibridez, entre o real e o ficcional, entre a observação quotidiana e o voo da imaginação, tal como sublinhado por muitos estudiosos do género, em Portugal e em outros países, como Antonio Candido (1992).

Em alguns textos, sobressai mesmo a hesitação genológica entre a crónica e o conto: "Podia ser um conto mas não é, aconteceu" (Carvalho, 2019: 20). E essa assunção da hibridez da crónica revela-se um traço essencial desta escrita de Maria Judite de Carvalho, tal como de Maria Teresa Horta - muitas dessas crónicas assumem a natureza de contos, com histórias concentradas e sugestivas, personagens, opções de focalização narrativa, brevíssimo enquadramento espácio-temporal, tal é a manifesta pulsão ficcional desta escrita, mesmo sob o disfarce da narrativa relatada: "Contaram-me esta história mas não ponho as mãos no fogo pela sua veracidade" (Carvalho, 2019: 62). Afinal, o real quotidiano está repleto de situações que despertam o voo imaginativo da crónica, tudo dependendo da desenvolta capacidade de observação e da sensibilidade vibrátil. E tudo com frequente recurso a uma memória grávida de evocações, "porque não se deita fora o passado" (Carvalho, 2019: 27).

Entre as figuras evocadas nesta escrita, entre o real e o ficcional, mal a leitura se inicia, destacam-se os perfis femininos, envoltos numa enorme sensibilidade potenciada pela focalização de primeira pessoa: a pálida e senil idosa de um prédio lisboeta, com a necessidade de regressar ao passado da sua memória afectiva; a oferta de um gravador a uma mulher e o desejo de ouvir "frases tranquilizadoras" sobre a amizade ou sobre o 
amor; a anónima empregada doméstica e o recorte rápido de Florbela Espanca; a atração das mulheres pelas elegantes modas de Paris; as senhoras de certa idade e as suas viagens organizadas de turismo; o rosto memorável de uma jovem da caixa de um armazém com "cara ingrata"; as mulheres e os tranquilos passeios de domingo; a jovem desinteressada do guichet; a mulher triste e curvada que cose para fora; a jovem luminosa que, descendo a avenida, encarnava a Primavera de Botticelli; a memorável mulher de mão na cinta e pelo na venta...; entre tantos outros perfis de mulheres mais ou menos alienadas, muitas vezes empurradas para a margem social e do espaço não político, em que à Mulher é mesmo dificultada a consciência da sua própria identidade.

Neste enorme cortejo de figuras femininas que desfilam pelos seus textos, à cronista importa sobretudo observar o perfil de mulheres anónimas da cidade - jovens, adultas ou idosas (de criadas domésticas e empregadas de comércio a funcionárias de de repartições públicas) -, escravas da sua condição, presas à esgotante monotonia dos seus trabalhos, tantas vezes "mulheres áridas e exaustas, portanto agressivas". A própria voz autoral da crónica tem plena consciência desta ênfase no feminino ao nível do seu retrato da teia urbana: "Porque falo das mulheres e não dos homens?" (Carvalho, 2019: 47). Há uma indisfarçável empatia e um imperativo ético subjacentes.

No espaço conflitual da cidade, enquanto cronótopo de uma certa época, deparamonos com mulheres que talvez não tenham consciência da erosão da sua juventude, fechadas nas múltiplas "gaiolas" da vida, pobres e exploradas, frágeis ou resistentes, de quem por vezes, espontaneamente, brotam gritos de alma, em histórias sem história, aparentemente, no interminável palco da vida quotidiana (cf. Carvalho, 2019: 63). Há existências assim, sem nada de singular a distingui-las, como se representassem o protótipo da mulher, como, aliás, expressamente acentua a cronista: "Era um protótipo, o da mulher em quem não se repara e que dir-se-ia fazer tudo para passar despercebida" (Carvalho, 2019: 81). Havia que dar voz a esses seres apagados.

É neste horizonte que se vai construindo a tessitura da cidade e o seu sentido, em Maria Judite de Carvalho, como espaço por excelência de intersubjectividade, feito de inúmeros relances, figuras e incidentes quotidianos (cf. Prata, 2010: 98 ss.). Maria Judite de Carvalho tem plena consciência que o ethos jornalístico, no seu afã noticioso, não abarca toda a realidade das coisas e das pessoas, havendo assim espaço para a singularidade da escrita cronística: "Não, os jornais felizmente não contam as pequenas coisas terríveis que acontecem todos os dias, a todas as horas, em todos os minutos e segundos, para além das paredes mestras desta cidade, deste País, deste mundo." (Carvalho, 1979: 80). Assumidamente, a crónica assume-se como o outro olhar.

"Da minha janela não vejo o vento", mas talvez essas pequenas coisas de que a vida urbana se tece (Carvalho, 2019: 134). Porém, definitivamente, através destas crónicascontos de A Janela Fingida, vê-se o mundo de Maria Judite de Carvalho e a sociedade contemporânea, não através de janelas falsas ou fingidas (cf. Carvalho, 2019: 37-38), 
mas antes de uma janela singular, subjectiva e emocionada, magoada e ternurenta. Afinal, contrariando essa realidade evoicada, homens ou mulheres, todos desejam saber se podem um dia ser felizes (Carvalho, 2019: 40).

Sem grande consciência da sua sensualidade, são estas mulheres anónimas e comuns que habitam os dias, "que nunca se repetem porque cada momento é diferente e tem, por assim dizer, a sua impressão digital" (Carvalho, 2019: 85). Por tudo isto, o escritor e jornalista A. Batista-Bastos (1975: 13) não hesita em sustentar que A Janela Fingida pode ser lida como um "romance fragmentário", constituído de pequenos quadros, o "romance desses dias". Esta é, com efeito, uma forma singular de captar o aroma do tempo, título de uma das suas crónicas, a crónica quotidiana (ficcionada ou não) deste Portugal do fim do Estado Novo, através da arte de coleccionar pequenos e reveladores instantes e episódios, num mosaico tão expressivo e revelador (cf. Morão et alii, 2015).

\section{Agustina Bessa-Luís e a vida do pensamento}

Das três autoras do nosso corpus, as crónicas de Agustina Bessa-Luís (1996), recolhidas em Alegria do Mundo, distinguem-se por um carácter mais cultural e ensaístico, e menos "literário" ou ficcional, se comparadas com os textos das outras autoras. Nas crónicas de Maria Judite de Carvalho e de Maria Teresa Horta, o cunho literário e a diluição das fronteiras entre a crónica e a ficção são por demais evidentes, sendo muitas vezes difícil deslindar uma taxionomia genológica que, superando a hibridez assumida, separe a crónica do conto ou da narrativa breve. Diferentemente, na escrita da consagrada autora de $A$ Sibila sobressai uma marcada tendência para a reflexão crítico-ensaística, num horizonte cultural marcadamente interarístico e cosmopolita, com destaque para a paisagem e identidade cultural mediterrânica.

Com efeito, nesses escritos da colaboração regular na imprensa nos anos de 1965-1969, deparamo-nos com textos normalmente breves, escritos com certa periodicidade, numa crónica dominada por um discurso altivo, provocatório e extremamente culto, com uma natural tendência para a frase lapidar e até aforismática, quando não paradoxal. Estamos assim diante de uma crónica mais erudita, com uma vocação ensaística e digressiva. Também por isso, pode dizer-se que a arte da crónica participa do estatuto da grande literatura, desafiando e não deixando ninguém indiferente: "Neste mundo febril e desatento do indivíduo, a obra culta tem que ter a violência de uma agressão" (Bessa-Luís, 1996: 86); e em outro passo, não hesita em reafirmar a sua frontalidade em matéria de escrita cronística: "Houve quem me achasse ambígua e irritante a propósito de Nureyev. Mas sou assim a propósito de tudo o que seja disponível à opinião dos 
outros." (Bessa-Luís, 1996: 209). Aliás, a escritora sempre cultivou uma auto-imagem de mulher culta e muito assertiva, dada a pronunciamentos desconcertantes e provocatório, a lembrar textos dispersos congéneres de Marguerite Yourcenar.

Neste contexto, não surpreende e impressiona a densidade intertextual dos textos cronísticos de Agustina - da Mitologia clássica e da Bíblia à Filosofia, da História e da Política à Literatura e às demais Artes (pintura, cinema, etc.), à leitora voraz nada do que é humano lhe parece ser alheio. A "vivência quotidiana" (Bessa-Luís, 1996: 269) mostrase inimaginável sem Cultura, nas suas mais variadas manifestações, num horizonte bem cosmopolita e, portanto, bem longe de visões fechadamente nacionalistas, caras à tradicional propaganda do regime.

À cronista importa sobretudo a vida do pensamento (Bessa-Luís, 1996: 24); mais do que a anotação cronística de acontecimentos quotidianos, interessa o olhar crítico para além dos eventos do dia a dia, com a memória ampla da História e da Cultura. Nessa memória, a cronista tem mesmo rápidas incursões na história da imprensa portuguesa, como quando particulariza as publicações setecentistas Gazeta de Lisboa e o Portugal Ilustrado pelo Sexo Feminino (cf. Bessa-Luís, 1996: 90, 113-115). Como relatado numa das crónicas, esta última publicação relatava histórias de várias mulheres que se destacaram na História por "famosas coisas".

Consequentemente, face ao afirmado, estas crónicas mostram uma atração por tudo o que envolve, directa ou indirectamente o "contrato com a literatura" (Bessa-Luís, 1996: 108), ou não fosse a autora uma consagrada e heterodoxa romancista. Afinal de contas, o intelectual ou "artista" é (deve ser) sempre "um fermento indispensável na sociedade" (Bessa-Luís, 1996: 118). Do que decorre um papel relevante para a cronista, incumbindoIhe pensar a realidade com olhar reflexivo e memória cultural enciclopédica, cujos interesses vão desde a Antiguidade clássica greco-latina até à Arte e ao Cinema contemporâneos. Para esta cronista, "a cultura, [que] é a parte mais considerável da felicidade humana" (Bessa-Luís, 1996: 34).

Nessa amplitude cultural enciclopédica e torrencial, como antes sugerido, assumem particular evidência o humor e a ironia, numa postura de sobranceria e acutilância raras no panorama literário português, sobretudo vindo de uma mulher escritora. E a partir dessa perspectiva feminina e ucrónica, não surpreende o seu olhar empático sobre outras mulheres, a começar por figuras destacadas da história do pensamento e da cultura ocidentais, como Santa Teresa, levando a cronista a destacar "a magistral intuição desta mulher" (Bessa-Luís, 1996: 24); a figura mítico-passional de Inês de Castro (Bessa-Luís, 1996: 65-68); sem esquecer figuras mítico-literárias como a trágica Ifigénia grega (Bessa-Luís, 1996: 125).

Nesse espetáculo do mundo que passa pelas suas crónicas, Agustina Bessa-Luís dedica uma atenção especial à "condição da mulher", aliás num dos mais longos textos de 
Alegria do Mundo, datado de 15 de Novembro de 1967, curiosamente uns meses antes da revolução cultural do Maio de 68 em França. (A cronista tem plena consciência, aliás, do ascendente da cultura francesa quando afirma com humor crítico: "Em Portugal a cultura cai ainda dos castanheiros das Tulherias; é um francesismo, quando não é, além disso, uma intriga de jacobinos" (Bessa-Luís, 1996: 283)). A grande questão analisada nessa crónica-ensaio é precisamente "o problema da emancipação da mulher" na sociedade da época, com destaque para os vários desafios que se colocam à sua "carreira" e integração plena na "vida da comunidade" (Bessa-Luís, 1996: 156).

Sem demonstrar empatia por movimentos feministas, mas reconhecendo o "caso-crise" então vivido, a autora detém-se em considerações sobre a "dignidade", o "espírito" ou a "feminilidade", traços da sua "feminina condição", de que não pode abdicar nesse caminho de emancipação (Bessa-Luís, 1996: 157-158), porque, para a culta cronista, há verdades indiscutíveis: primeira, a mulher tem de vencer as batalhas da sua emancipação sem perder a sua feminilidade; segunda, a mulher portuguesa ainda estava ainda longe dessa "vanguarda do acontecimento" que abriu novos progressos à sua condição social, desde a vida familiar à profissão, havendo os perigos dos estereótipos nesse "espírito de renovação" ou evolução de comportamento e de mentalidades: "Espero que a mulher portuguesa, sobre a qual estou a escrever, não acabe por ser a intelectual ou a folclórica" (Bessa-Luís, 1996: 162).

Nessa evolução, reconhece, pesa ainda uma herança multissecular, sob a forma de "aprendizagem da humildade", manifesta no "drama biológico" e em tudo o que está implicado na defesa da sua prole (Bessa-Luís, 1996: 163). Só recentemente a mulher, sentindo-se mais livre desse enorme peso ancestral, começa a "deliberar acerca do seu próprio destino", com consequências imediatas nesse processo de "libertação da mulher", a par de uma "nova ética", que inclui a liberdade, a profissão, o casamento, entre outros factores, com vista a uma felicidade mais plena, a par de profundas consequências para a tradicional ordem masculina e patriarcal: "Uma mulher assim começa por trazer complicações ao mundo dos homens" (Bessa-Luís, 1996: 164).

Porém, como anota, o assunto é sério e complexo demais para ser analisado na escrita leve e breve da crónica: "Nada há de espectacular nesse processo de libertação; não houve nada de acidental, é apenas um facto que não pertence à crónica ligeira e sensacionalista." (Bessa-Luís, 1996: 165). Não sendo um tema central das crónicas de Agustina, o lugar da mulher na nova sociedade da década de 1960 não poderia ser ignorado. Aliás, a reflexão sobre a condição da mulher na sociedade patriarcal revela-se um tema verdadeiramente estruturante da obra ficcional da autora de Três Mulheres com Máscara de Ferro, com destaque para figuras femininas superiores e insubmissas, complexas e subversivas (como Quina, Ema e Fanny, entre muitas outras), desprezando enraizados estereótipos e questionando virilmente o seu papel no mundo (cf. Magalhães, 1989: 245). 


\section{Maria Teresa Horta e o desencanto quotidiano do peso dos dias}

Em Quotidiano Instável - nome original da coluna jornalística semanal - Maria Teresa Horta (2019) recolhe recentemente as crónicas publicadas no suplemento literário "Literatura e Arte" do jornal A Capital (1968-1972), na sequência da colaboração de Álvaro Salema. Também Natércia Freire dirige por esta altura o "Artes e Letras" do jornal Diário de Notícias. Nestes suplementos de dois importantes jornais lisboetas encontramos um importante repositório do jornalismo literário português do terceiro quartel do séc. XX. Cabe salientar que, fundado em 1911 e reaparecido nesta altura, dirigido por Norberto Lopes e depois por Manuel José Homem de Mello, o jornal $A$ Capital era um vespertino lisboeta conhecido pelo ousado distanciamento face ao regime do Estado Novo.

Resgatadas do esquecimento do arquivo do jornal ("Textos revistos pela autora em 2019", segundo informação paratextual), as crónicas de Maria Teresa Horta observam igualmente os traços fundamentais do género - desde um "timbre jornalístico" e o carácter regular, a par da brevidade e da actualidade. Ao mesmo tempo, torna-se muito evidente, na sua patente hibridez, a ausência de fronteiras muito nítidas entre a crónica e a ficção praticada pela autora (cf. Fernandes, 2019: 10).

De facto, tal como em Maria Judite de Carvalho, as crónicas de Maria Teresa Horta também se distinguem por uma assumida porosidade entre a escrita da crónica jornalística de óbvio cunho literário e a ficção literária da autora, nomeadamente o conto ou o microconto. Não surpreende, aliás, que esse aspecto já tenha sido salientado pela crítica que analisou a obra literária da autora, nomeadamente quando se sustenta que as crónicas de Quotidiano Instável representaram um campo experimental para a escrita de uma obra literária da autora de Ambas as Mãos sobre o Corpo (de 1970), confirmando assim um efeito de contaminação, como referido por João Palma-Ferreira (1970: 3) e por Ana Raquel Fernandes (2019: 11).

No caso de Maria Teresa Horta, talvez uma das mais salientes singularidades resida no estilo sensorial que autora imprime à sua escrita em geral, por um lado; e, por outro, a acentuação do feminino e do erótico, também bem visível nestas suas crónicas. A partir de uma certa visão ou sobrevoo do real quotidiano, misturando a observação, a memória e o voo ficcional, a escrita cronística de Maria Teresa Horta valoriza desde logo uma voz feminina para as suas crónicas, reiterando uma focalização subjectiva de primeira pessoa. Também aqui, estamos diante de uma voz que, desde logo, se vai condoendo empaticamente diante do destino das "mulheres que esquecem as fábricas onde trabalham horas sem fim"; ou que nos retrata uma "mulher fechada, incerta e triste", uma mulher assente numa "base raivosa e tensa, nunca passiva" (Horta, 2019: $33,47)$. 
Como sugerido, estas crónicas retomam linhas temáticas muito centrais na escrita literária da autora, com destaque para o amor, nos mais diversos registos, a par de uma ênfase no erotismo manifesto, tendências que constituem uma forma de ousadia e de subversão de uma certa moral vigente na época: ora se fala reiteradamente nas "pernas macias, altas" e sensuais de um corpo inquieto que se insinua (Horta, 2019: 51); ora se alude, de diversos modos, ao desejo erótico como "desassossego apressado...", depois de uma "ansiosa espera" (Horta, 2019: 55, 36); ora ainda se menciona o pulsar erótico dos corpos, com o calor da sua nudez (Horta, 2019: 63, 67). Mas sempre com o medo a rondar, originando o desamparo, a solidão e a angústia: “O medo subiu de novo como um novelo, grosso, quente, redondo" (Horta, 2019: 68).

Em muitas destas crónicas ergue-se a imagem forte e obsessiva de um corpo feminino, sensual e erótico, como evidência essencial e, sobretudo, como arma de arremesso contra a moral e o medo dominantes: "O corpo intacto, jovem na sua magreza ágil, de ancas estreitas e pernas delgadas, individualizado sob os seus vestidos soltos, justo nas suas saias finas ou nas blusas macias que aderem ao de leve sobre os seios" (Horta, 2019: 76). Numa palavra, a imagem de uma "mulher que dominava o tempo com o movimento flexível do seu corpo harmonioso e tenso nas ancas escorridas" (Horta, 2019: 82). Mas sempre as imagens (proibidas) de um belo e macio corpo de mulher, enquanto fruto proibido e apetitoso, dotado de uma sede febril, como um vício - "o corpo macio debaixo do vestido, como se fosse um fruto" (Horta, 2019: 86); de uma mulher sensual e voraz, que concretiza o seu desejo na posse do corpo masculino (cf. Horta, 2019: 98); e ainda de rituais de sedução sexual, vibrando através de um corpo rebelde e escaldante (cf. 104, 130): “a tua boca está húmida e quente" (Horta, 2019: 122); "Sentindo o desejo a debater-se, a pulsar como um pequeno animal na garganta, no ventre, nos pulsos estreitos" (Horta, 2019: 128).

Neste género ambíguo de crónica-conto, emergem constantes referências ao corpo e à intimidade, à sensualidade e ao desejo, como acontecia na escrita marcante da autora de Minha Senhora de Mim (de 1971), obra desencadeadora de polémica e mesmo de apreensão por parte do governo de Marcelo Caetano, sendo o nome da cronista omitido do suplemento "Literatura e Arte" do jornal A Capital. Mais uma vez, a força subversiva de Eros revelava o seu poder provocador e intensamente iconoclasta, marcando de forma profunda uma época, atingindo outro ponto culminante com a já referida publicação das Novas Cartas Portuguesas, em 1972, de que foi co-autora.

Neste contexto repressivo, aliás, lateral às crónicas de $A$ Capital, revela-se significativo o texto aqui recolhido em apêndice nesta edição das crónicas, intitulado "Fábula das três mulheres que caminhavam no deserto" (cf. Horta, 2019: 169-172), aludindo ao "processo das três Marias", que "já atraía as atenções da imprensa internacional" em cujo incipit se lê esta linguagem metafórica, manifestamente alusiva ao caso polémico e judicial das Novas Cartas Portuguesas, além de invocativa do valor maior da liberdade: 
"Caminhavam três mulheres no deserto, transportando consigo poucas posses: haveres de corpo e coragem". Sobressai a imagem axial da mulher-coragem.

Enfim, tudo concorre para a concretização de grande novidade e de efeito provocador destas crónicas insólitas, sobretudo num "tempo peganhento" (Horta, 2019: 26), enquanto textos capazes de, corajosamente, "alegrar a monotonia do tom neutro", como o do tempo que se vivia em Portugal no final da década de 1960. Crónicas como estas mostram-se exemplares pela criatividade literária e pela incómoda novidade no "ambiente asfixiante" vivido nesse Portugal, em que "as pessoas falavam baixo", ainda mais as mulheres, todos movidos pelo medo omnipresente (Horta, 2019: 37), tantas vezes dando origem à dor e às lágrimas, num tempo que se arrastava com o "pesos dos dias" (Horta, 2019: 76).

Amar em total liberdade, mesmo que de forma clandestina, amar com um corpo resoluto, sedento e voraz, era a única forma de superação do medo de uma "mulher [que] vestiu o seu comprido vestido azul a deixar ver o peito fresco e jovem", estilhaçando certas convenções morais (Horta, 2019: 159). Há referências muito raras a um tempo histórico bem concreto - como a Missão Apolo 70 e aos astronautas Neil Amstrong e Buzze Aldrin (102) -, mas é sobretudo de uma sociedade concreta e imediata que se tecem estas crónicas, a de um Portugal amordaçado da transição dos anos de 1960 para 1970. É desde quotidiano instável, dominado pelo peso dos dias, à espera da libertação, que nos falam eloquentemente as crónicas de Maria Teresa Horta. Porque, afinal, senhora das artes da sedução e de recalcados ardores sensuais, "a mulher sabe bem o papel que lhe cabe" (Horta, 2019: 160), quando se entrega à paixão sem reservas, fugindo ao "enorme cansaço do mundo" (Horta, 2019: 168). Trata-se, pois, de assumir esse papel, com a coragem dos riscos inerentes e a vontade irreprimível da mudança.

\section{Conclusão: força das crónicas (diversamente) femininas}

Cremos que, face aos propósitos enunciados no início deste texto, depois da análise desenvolvida, podemos inferir algumas breves conclusões: primeira, estamos perante um corpus de crónicas jornalísticas que coincidem temporalmente com um certo retrato desta época de final do regime do Estado Novo em Portugal. No seu conjunto, estas crónicas traçam um panorama de um tempo suspenso, em que a Mulher e o feminino tinham consciência da necessidade de uma profunda mudança. Era imprerioso dizer a urgência do feminino e da feminilidade. E apesar das assinaladas constrições, estas poderosas vozes femininas conquistaram o seu espaço no decisivo espaço público, 
sendo muito influentes na valorização do lugar da Mulher e na difícil conquita dos seus direitos durante o Estado Novo (cf. Pimental \& Melo, 2015).

Ao mesmo tempo e por consequência, lidas comparativamente, estas crónicas são muito elucidativas da preocupação de intervir na sociedade e na cultura portuguesas da época, apesar da dificuldade ao nível da falta de liberdade de expressão, coarctada pela referida vigência da Censura. Por isso, é notório o investimento linguístico em certas formulações metafóricas e simbólicas, numa linguagem rica de implícitos e de formas indirectas, ao apontar para certos tópicos e temas essenciais à mudança de mentalidades. Há uma verdadeira poética da alusão que atravessa estas crónicas.

Ao mesmo tempo, é fundamental sublinhar que, na assumida diversidade de estilos, nenhuma destas cronistas aceitou escrever "crónicas femininas", no sentido redutor do atributo, sobretudo neste contexto temporal. Essa é também a marca destas grandes e ousadas cronistas, fugindo ao reducionismo de um jornalismo feminino. Numa das suas crónicas para o Jornal do Brasil, datada de 30 de maio de 1970, isto é, exactamente pela mesma altura destas cronistas portuguesas, também Clarice Lispector (2018: 231) recorda o convite recebido para escrever crónicas "para mulheres", isto é, sobre "assuntos estritamente fúteis-femininos, na expressão em que feminino é geralmente tomado pelos homens e mesmo pelas próprias mulheres: como se a mulher fizesse parte de uma comunidade fechada à parte, e de certo modo segregada."

Aliás, em outra crónica, a mesma Clarice refere-se a Natércia Freire, que Ihe solicitara colaboração para o Suplemento de "Artes e Letras" do jornal lisboeta antes referido, Diário de Notícias, o que indicia a existência de uma certa empatia feminina na imprensa da época. Ao expressar uma declaração de amor à língua portuguesa, também Clarice Lispector (cf. 2018: 80) não deixa de assinalar a falta de ductilidade da língua para expressar, por exemplo, certas "subtilezas", obrigando a cronista a um esforçado trabalho sobre a língua, de modo a torná-la mais maleável. Para usarmos uma imagem poderosa da cronista brasileira do Jornal do Brasil, e como destacado antes, também as crónicas destas autoras portuguesas constituem muitas vezes um "grito" contra determinado statu quo vigente (cf. Lispector, 2918: 66).

Dentro das várias limitações referidas, confluentes num determinado contexto histórico e ideológico do prolongado final do Estado Novo - materializado conhecido lema de Salazar: "Tudo pela Nação, nada contra a Nação" -, estas crónicas jornalísticas e literárias constituíram uma forma muito relevante de actuação, de pronunciamento e de intervenção no espaço público, num exercício de cidadania face a uma sociedade dominada pelo homem, pelo autoritarismo do regime e pela sua eficaz máquina de propaganda nacionalista (cf. Paulo \& Torgal, 2015; e Tengarrinha, 2006). Cada uma ao seu modo, estas autoras resistiram, de forma persistente, na causa da emancipação da Mulher. 
Enquanto tribuna de pronunciamento, a crónica jornalística era à sua maneira uma forma de intervenção através da pena, sob a via intelectual de actuação sobre as ideias. Outra forma bem distinta era a da actuação das Brigadas Revolucionárias (tendo Isabel do Carmo como elemento fundador), através da luta armada, de que nos fala Isabel Lindim (2012), em Mulheres de Armas, precisamente desde 1970 a 1974. São duas maneiras bem distintas de intervenção sobre a sociedade em geral e, em particular, sobre o regime de antes do 25 de Abril de 1974, ambas protagonizadas por mulheres; formas que demonstravam eloquentemente o descontentamento perante um regime político que teimava em perdurar, condicionando fortemente a evolução da sociedade portuguesa de então. E porque é preciso ter memória, é também destas lutas que nos fala a recente exposição "Mulheres e Resistência - Novas Cartas Portuguesas e outras lutas", patente no Museu do Aljube - Resistência e Liberdade, patente até final deste ano de 2021.

Em suma, nesse retrato de um Portugal cinzento e fechado, sobressai claramente, entre outros aspectos relevantes, o lugar da mulher e da sua condição, num tempo em que ocorriam aceleradas transformações de mentalidades na Europa e no mundo ocidental. Nestas memoráveis crónicas, na diversidade antes ilustrada, procede-se à invenção do quotidiano, parafraseando o estudo teórico de Michel de Certeau (cf. 2004: 142), na medida em que a espacialidade heterogénea e antropológica da cidade, enquanto espaço público privilegiado, é sempre o resultado das operações, práticas ou performances dos seus habitantes.

\section{Referencias bibliográficas}

BARRENO, M. I.; Horta, M. T.; Costa, M. V. (2010): Novas Cartas Portuguesas, Lisboa, D. Quixote (ed. anotada; org. Ana Luísa Amaral).

BAPTISTA-BASTOS, A. (1975): "Maria Judite de Carvalho: uma ternura magoada", in Maria Judite de Carvalho, A Janela Fingida, Lisboa, Seara Nova, pp. 11-18.

BESSA-LUÍS, A. (1996): A Alegria do Mundo, I (Escritos dos anos de 1965-1969), Lisboa, Guimarães Editores.

CANDIDO, A. (1992): A vida ao rés-do-chão, in Candido, A. (org.). A Crônica: o gênero, sua fixação e suas transformações no Brasil, São Paulo, Ed. Unicamp; Rio de Janeiro, Fund. Casa Rui Barbosa, pp. 13-22.

CARMO, C. I. (ed.) (2018): A Visagem do Cronista: antologia de crónica autobiográfica portuguesa (séculos XX-XXI), 2 vols., Lisboa, Arranha Céus. 
CARVALHO, M. J. (1979): O Homem no Arame, Amadora, Bertrand.

- (2019), A Janela Fingida [1975], in Obras Completas, vol. IV, Coimbra, Minotauro.

CERTEAU, M. (2004): L’Invention du Quotidien, vol. 1. Paris, Éd. Gallimard.

COSTA, M. V. (1973): Desescrita, Porto, Afrontamento.

FERNANDES, A. R. (2019): “Quotidiano Instável: dispersão ou coesão?”, in Maria Teresa Horta, Quotidiano Instável, Coimbra, Minotauro, pp. 9-15.

FRANCO, G. (1993): A Censura à Imprensa (1820-1974), Lisboa, Universidade Católica Portuguesa-Imprensa Nacional.

HORTA, M. T. (2019): Quotidiano Instável: crónicas (1968-1972), Lisboa, D. Quixote.

LINDIM, I. (2012): Mulheres de Armas: histórias das brigadas revolucionárias - as acções armadas, os riscos, as motivações (Pref. de Isabel do Carmo), Lisboa, Objectiva.

LISPECTOR, C. (2018): Todas as Crónicas, Lisboa, Relógio d'Água.

MAGALHÃES, I. A. (1989): O Tempo das Mulheres, Lisboa, IN-CM.

MOURA, R. L. (2018): O Jornalismo nas Narrativas das Crônicas de Rachel de Queiroz e Maria Judite de Carvalho [Tese de doutoramento], Porto Alegre, PUCRS.

MORÃO, P.; RIBEIRO, C. A. (eds.) (2015): Maria Judite de Carvalho - Palavras, Tempo, Paisagem, Famalicão, Húmus / CEC.

PALMA-FERREIRA, J. (1970): "Crítica a Ambas as Mãos sobre o Corpo", in Suplemento "Literatura \& Arte", jornal A Capital, de 30 de Dezembro de 1970, pp. 3 e 6.

PAULO, H.; Torgal, L. R. (2015): “Cidadania, Nacionalismo e Propaganda Política”, in Ana Teresa Peixinho (et alii), 20 Anos de Jornalismo contra a Indiferença, Coimbra, Imprensa da Univ. de Coimbra, pp. 169-188.

PIMENTEL, I. F. (2000), História das Organizações Femininas no Estado Novo, Lisboa, Círculo de Leitores.

PIMENTEL, I. F. \& MELO, H. M. (2015): Mulheres Portuguesas, Lisboa, Clube do Autor.

PRATA, A. F. (2010): Práticas Narrativas da Cidade. Crónicas Urbanas de Carlos Drummond de Andrade, Maria Judite de Carvalho e Jacques Réda. Dissertação de Doutoramento em Estudos Literários - Literatura Comparada. Lisboa: Universidade de Lisboa. Disponível online (20.03.2021): http://repositorio.ul.pt/handle/10451/3048 
RAMOS, R. (coord.) (2015): História de Portugal, 8ae ed., Lisboa, Esfera do Caos.

RODRIGUES, G. A. (1980): Breve História da Censura Literária, Lisboa, ICALP / Biblioteca Breve.

ROSAS, F. (1994): História de Portugal - O Estado Novo (1926-1974), vol. 7, José Mattoso (dir.), Lisboa, Círculo de Leitores.

— (2015): Salazar e o Poder: a arte de saber durar, Lisboa, Tinta da China.

TENGARRINHA, J. M. (2006): Imprensa e Opinião Pública em Portugal, Coimbra, Minerva. 